\title{
Learning from Online Video Lectures
}

\author{
H. David Brecht \\ California State University, Sacramento, California, USA \\ Brecht@csus.edu; gomailroof@comcast.net \\ Executive Summary
}

This study empirically examines the instructional value of online video lectures - videos that a course's instructor prepares to supplement classroom or online-broadcast lectures. The study examines data from a classroom course, where the videos have a slower, more step-by-step lecture style than the classroom lectures; student use of videos is voluntary, can be tailored by students to meet their learning and topic-review needs, and can occur when and where students learn most effectively. The study's specific objectives are to identify and measure types of learning benefits that video lectures provide, gauge students' acceptance and use of this form of computer-based instruction, and compare results from alternative video designs to determine if learning is differently affected.

The course is highly technical (financial accounting) and is required of all business school students as they enter the school. The university is middle-tier and located in a medium-sized metropolitan area. Students are highly varied in their academic abilities and motivation, and they often have substantial off-campus job responsibilities.

Three video designs were tested, each with an alternative learning environment designed into the videos. Design 1 had a complete absence of attention to relief and change-of-pace elements. Design 2 included graphics/cartoons and sounds/music clips that were strongly presented to provide relief from study tedium. Design 3 used a greatly reduced number of graphics and sounds and subtly presented them so that they did not command viewer attention. Learning benefits are consistently best with design 2 .

Findings are based on analysis of survey data and grade distributions. They include comparisons of with-videos and no-videos sample data. The most significant findings are that video lectures are used by students for tutorial help, they improve initial learning, they reduce dropout rates, and they improve course grades.

Although the study is for a classroom course with the videos provided online, it is expected that video lectures will have similar or greater use and value in an online course when live-instruction and discussion are limited. Findings indicate that a very large percentage of students who watch the videos use them as a helpful tutoring resource and receive several types of improved-learning

Material published as part of this publication, either on-line or in print, is copyrighted by the Informing Science Institute. Permission to make digital or paper copy of part or all of these works for personal or classroom use is granted without fee provided that the copies are not made or distributed for profit or commercial advantage AND that the copies 1) bear this notice in full and 2) give the full citation on the first page. It is permissible to abstract these works so long as credit is given. To copy in all other cases or to republish or to post on a server or to redistribute to lists requires specific permission and payment of a fee. Contact Publisher@,InformingScience.org to request redistribution permission. benefits including improvement in topic understanding, better grades, and greater ease of learning.

The weakest students are especially benefited, with significantly reduced course withdrawal rates. Use of video lectures occurs when alternative study resources with the same topic content are always available. 
Keywords: e-learning, computer-based learning, instructional videos, video lectures, computerbased tutoring, technology and self-paced learning, online pedagogy, video learningenvironments

\section{Introduction}

This study gathers performance data regarding online video lectures that are used for an inresidence, classroom course. "Video lectures" are instructional videos prepared by the course instructor to supplement classroom lectures. Their use is not essential to complete the course and is voluntary.

The videos have the same content and subject rigor as the classroom lectures, labs, homework, and exams, but are portable and can be studied when a student wants and at the student's individual learning pace. The lecture style is slower and more step-by-step than in classroom lectures.

Video lectures are made up of the instructor's audio narrative added to Microsoft Office screens that display topic content. Lectures are encoded in video files and distributed online, which enables their use in either classroom or online courses. Students in both course settings have the common goal of using study resources that improve learning and grades. If classroom students use and benefit from online video-lectures, online students from similar student populations should be able to use them and benefit.

The study's primary objectives are to identify and measure types of learning benefits that video lectures provide. The course studied is introductory to the discipline, and students generally have no background or pre-existing cognitive development in the subject. Thus, supplemental video lectures are expected to improve learning significantly.

A second objective of the study is to gauge students' acceptance and use of this form of computerbased instruction. The course was not advertised as computer-enhanced, and the videos were voluntarily used when classroom lectures covered the same material and alternative study resources were always available. The study's results should extend to or be more favorable for online courses where students are self-selected to use online resources.

A third objective of the study is to compare results from alternative video designs to determine if learning is differently affected. The most effective design elements are identified.

The article's organization is as follows. In sequence, the literature's theoretical foundations for the study are discussed, the study's video designs are described, and the types of test data and data analysis methods are explained.

Then, student and course characteristics are described. This discussion includes aspects of the university's educational environment and the percentages of students using the videos and responding to a survey. The potential for sampling, survey response, and survey non-response bias in the test data is subsequently discussed.

The remainder of the article contains the study's results, the advantages, difficulties, and limitations in video-lecture use, and the conclusions. In the "results" sections, six investigation areas are studied. They are the effects of video lectures on initial learning and midterm exam review, on learning with different types of topic difficulty, in providing tutoring help, on course dropout rates, in providing effective final exam review, and on course grades.

\section{Theoretical Foundations}

Existing research demonstrates that formal supplemental-instruction programs improve student grades and reduce failure rates. For example, in this study's academic area (accounting), Jones 
and Fields (2001) successfully used special classroom sessions that were run by specially trained session-leaders.

Phelps and Evans (2006) used a supplemental instruction program to improve student performance in developmental mathematics. Martin, Arendale, and Blanc (1997) demonstrate the learning value of supplemental instruction based on a combination of live-lecture videos and live tutoring of the videos' content. Their application focuses on students who were unprepared for rigorous academic challenge.

As informal supplemental instruction, video lectures provide instructor-delivered models of reasoning and problem solving. This reduces cognitive load for beginning students and is expected to increase learning and grade performance. Underlying research with similar results is found in Merrill, Reiser, Ranney, and Trafton (1992) and in Kirschner (2002).

Other research examines the effects on learning of interactive study, student control of the learning process, and active engagement in learning. Bryant and Hunton (2000) discuss educational technology's attributes from the perspective of behavioral and cognitive learning theory. They include an examination of learning outcomes associated with interactive participation and learner control.

The Active Learning Online Team (2011) finds that learning is active when students seek explanations. Adler and Milne (1995) apply instructional scaffolding (Rosenshine \& Meister, 1992) to demonstrate the importance of student control of the learning process to long-lasting learning. Mabey, Topham, and Kaye (1998) study the importance of computer-mediated learning environments to learning tasks, where students control the learning process and influence which content is studied.

In the current study, features of interactive study, student control, and active learning exist in the use of video lectures. The course instructor controls available content, but students may choose the segments of the video lectures they want to study. They can pause the lecture while they think through the material, and they can repeat explanations until they are fully understood.

Zhang, Zhou, Briggs, and Nunamaker (2006) studied interactive video where video segments can be directly chosen for study. The video is divided into small segments that are played through an access-selection interface. The study finds that this direct choice and play interaction improves learning. The current study uses sequential search to select a lecture segment for study.

Moreno (2006) maintains that media characteristics affect technology-based learning. The current study's alternative video designs and video learning-environments test Moreno's hypothesis. Comparisons of learning effects identify the most beneficial design elements.

Lesser and Pearl (2008) and Van Wyk (2011) use topic-relevant cartoons and songs to define learning environments. In the current study, both topic-relevant and not topic-relevant cartoons are used. Not-relevant cartoons are used for their expected appeal in adding fun to the studying process.

Nemanich, Banks, and Vera (2009) find that content relevance and social richness in a course's learning environment are positively associated with student enjoyment and performance in traditional classroom courses. For technologically delivered information, Nicholson, Nicholson, and Valacich (2008) find that less complexity and more sensory-richness increase student interest and performance. Additionally, Bryant and Hunton (2000) examine the influence of visual and audio elements on learning outcomes in distance education.

In the current study, video content is highly relevant to the course's learning objectives and students' exam performance. Content formats and topic-development techniques are used to reduce complexity, and production values and relief/change-of-pace elements are surrogates for social 
richness. The a priori expectation was that these elements increase student enjoyment of the learning process and learning performance.

In the area of tutoring, Habley and McClanahan (2004) identify tutoring as one of the five most important factors in increasing student academic success and course retention. The current study tests students' perception of video lectures as tutorial help. Tutorial characteristics of the videos include more-slowly paced lectures with step-by-step topic explanations, the use of narrative from the course instructor, and students' ability to control the lecture (pauses and choice of topics).

An area of learning difficulty that can require tutoring is cognitive overload. Kalyuga (2009) connects a lack of subject background with cognitive overload, where students have difficulty integrating a large number of complex concepts and quantitative methods. This difficulty can result in motivational frustration and less effective learning (Merrill et al., 1992). Mayer and Moreno (2003) discuss ways to reduce cognitive load in multimedia learning.

The current study addresses cognitive overload in its design of content formats and topicdevelopment techniques. Further, tutoring is informal supplemental instruction and can keep students from floundering and becoming frustrated by a failure to learn. Sweller and Cooper (1985) and Sweller (1988) agree with a more procedural learning approach for beginning students where concepts and problem methods need to be fully explained.

More-advanced learning requires an alternative tutoring approach. Advanced learners may need help with learning to identify problem-solving errors, choosing solution methods that fit the errors, and managing their own learning (Merrill et al., 1992).

Tutoring through video lectures is course-section and instructor specific. In contrast, universities offer live tutoring for types of courses (Office of Minority Student Affairs, 2010). Comparing video-lecture and live tutoring, video lectures are more conveniently accessible at no cost to students and little cost to the university. They offer tutoring for students who have a learning-style preference for this learning medium (Mahoney \& Dziuban, 2000), and they help students who can benefit from tutoring but would not seek out a live tutor.

Simpson (2006) found that live-lecture videos enable student control of lecture delivery by pausing information transfer to fit the student's learning pace. Students can study the lectures without environmental distractions, at their convenience, and in a way that is consistent with their language comprehension needs when English is a second language. Video lectures prepared in the instructor's office provide similar benefits, but without recorded student-instructor discussion.

Regarding efforts to reduce student dropout rates, Lewis (2010) reports that large dropout rates in the USA are caused by more than half of first-year students being underprepared for college-level work. The current study finds that video lectures reduce course dropout rates. This result is consistent with dropout rates observed by Etter, Burmeister, and Elder (2000) when they used a formal program of supplemental classroom instruction.

Geri (2012) studied the dropout-rate effects of video lectures used in senior distance-education. Students failing an upper-division course with video lectures had reduced dropout rates for the academic program containing the course. They seem to have experienced learning-process benefits from using video lectures, which translated to a positive view of the academic program's learning processes and the possibility of eventual success.

Finally, the literature has addressed video length as follows. Whatley and Ahmad (2007) implicitly recognize limitations on the time students will commit to reviewing classroom lectures for exams. They developed 5-10 minute summary videos that outline main points from weekly classroom lectures. Students use PowerPoint slides for more-detailed information. 
Teaching Center (2011) uses YouTube videos that are mostly 2 minutes and at most 9 minutes in length. From a single web page, separate links are provided to prior-term exams and their solutions, to videos where exam solutions are explained by an instructor using a chalkboard, and to a concept-review video for each problem on the exam.

The current study provides full classroom lecture content in video lectures. Video length is progressively lowered in consecutive video-designs, ending up with a typical design 3 length of 1-11/4 hours.

\section{Video Designs}

Three different video designs are tested. Design 1 differs significantly from designs 2 and 3. Design 1 was developed and tested first. Following analysis of its survey results and consideration of anecdotal comments from students for design improvement, design 2 was developed. Design 2 was tested in a following course-term. Then, following analysis of the design 2 survey results, design 3 was developed and tested. The following three subsections give more detail for each video design

\section{Design 1}

Design 1 was encoded using Microsoft's Producer for PowerPoint software with the result of occasional screen instability. This software is implicitly intended for use with MS PowerPoint files and slides.

Contrary to this intended use, design 1 used Microsoft's Word, PowerPoint, and Excel software to prepare files for content-display. Additionally, design 1 included efforts to simulate classroom lecture characteristics by using keyboard writing to the screen, screen scrolling, and pointer movement during the narrative lecture. This screen activity during encoding may have added to the screen instability problems.

Video development focused solely on transferring classroom lecture content to students and ignored video-instruction as a unique learning resource.

It did not consider that the videos would be used independently of the classroom and thus not be supported by follow-up questions in live classroom sessions. No consideration was given to video learning as an independent, self-motivated, self-study experience. Moreover, the concept of a video learning-environment and its impact on student engagement in learning was not considered.

\section{Design 2}

Design 2 was encoded with more powerful video capture software. In addition, encoding demands were reduced by using only PowerPoint files, eliminating keyboard writing to the screen, eliminating scrolling, and reducing the frequency of pointer movements. These changes eliminated the encoding problems of design 1.

Content formats and topic-development techniques were redesigned to speed student orientation to screen content, increase intuitive recognition of how the parts fit into the whole for a set of concepts or a problem method, and increase understanding received for viewing-time spent. These changes capture information relationships more efficiently and quickly in a no questions and answers learning-environment.

To illustrate, a common-screen structure adds data to an initial screen of a solution to form a new screen. Successive screens are similarly formed as a problem's solution progresses. The final screen completely captures the data and solution-component relationships. This structure is in- 
tended to make successive solution steps more understandable. An added benefit of design 2 is its reduction of video lengths by an average of $24 \%$ compared to design 1.

Production values were upgraded with colors, gradients, and attention to page spacing. This intends to increase visual interest and ease of viewing. For relief and change-of-pace, graphics, animations, sounds, and music clips were displayed as new topics were started or screens opened. An element commands viewers' attention through the length of time it is presented and the amount of screen space used (for graphics).

Frequent display of a variety of elements also commands attention. All graphic and sound clips were easily accessible "off the shelf" and were either free or very inexpensive to obtain.

\section{Design 3}

Design 3 was encoded with the software used for design 2. It also continued design 2's content formats, topic-development techniques, and production values with minor improvements.

For example, screen formats were made more consistent throughout a video to speed content recognition. Pauses in lecture delivery were reduced in order to reduce video length (students can pause the video if they need additional time to assimilate content). The average video length was reduced by $7.5 \%$ compared to design 2 .

Design 3's significant difference from design 2 is in relief and change-of-pace elements. They were changed from strong to subtle because $36.8 \%$ and $35.3 \%$ of the design 2 students, for graphics and sounds, respectively, said strongly presented elements disrupted their study concentration. Subtle presentation involves less display time and frequency, the elimination of music, and the use of only topic-relevant cartoons.

In summary, design 1 has lower encoding quality than designs 2 and 3, lessening viewing quality and sensory ease. It does not use content formats that are designed to increase the speed with which self-studied video content is organized in students' thinking. Designs 2 and 3 include these improvements.

Similarly, design 1 does not use topic-development techniques designed to increase students' understanding of concepts and problem methods when self-studying videos. Designs 2 and 3 include these improvements. Also, design 1 does not have appealing production values, whereas designs 2 and 3 add elements to increase sensory appeal. Examples are richer colors and better spacing of content on a screen.

Finally, design 1 does not include relief and change-of-pace elements. These are graphics and sound clips that video designs 2 and 3 use in creating video learning-environments. The environments are intended to increase student interest and attentiveness and reduce impatience or boredom with studying.

Designs 2 and 3 are similar to each other in eliminating encoding problems and using better content formats and topic-development techniques. They are significantly different in their relief and change-of-pace elements. Design 2's elements are strongly presented and command viewers' attention. Design 3 subtly presents a reduced set of elements, with less interruption of a viewer's concentration. .

\section{Data Analysis Method}

The study's findings are based on survey data and grade distributions. Surveys were conducted near the end of the with-videos course sections (see the Appendix for the survey instrument). Survey questions refer to video use throughout the course excluding final exam preparation. An- 
swers to questions about course grades are based on students' graded work to date and expectations of final exam grades.

Survey responses are analyzed qualitatively and statistically. Qualitative analysis describes and evaluates relationships between video designs' characteristics and survey responses. Statistical analysis uses a one-sample, one-tailed binomial test to measure the significance of differences between yes and no responses, where $\mathrm{z}=((\mathrm{X} \pm .5)-\mathrm{NP}) / \sqrt{ } \mathrm{NPQ}$ (Siegel, 1956, pp. 40-42). The value $\mathrm{z}$ is defined for confidence levels of $\alpha=.01$ or .05 when used to reject the null hypothesis that the percentages of yes and no responses are equal. $\mathrm{P}$ is defined as $1 / 2$.

Yes/no survey responses were used rather than a more complex scale (such as a Likert 7-point scale) in order to reduce reflection effort for respondents and reduce the response time required. The objectives were to increase response rates and reduce response-bias caused by scaled responses that were not well thought out.

Yes/no survey responses are binomial, although the binomial rapidly tends toward the normal distribution with $p=1 / 2$ and $n>25$. Survey sample sizes for students using videos are in the $42-54$ range and are sufficiently large to use a binomial test with z-values tabulated for the normal distribution.

Grade distributions objectively measure learning and are analyzed qualitatively and statistically. Qualitative analysis is based on observations of grade distributions and evaluation of the effects of having/not-having video lectures or video design characteristics on grades.

Statistical analysis uses the nonparametric Kolmogorov-Smirnov two-sample test to measure the differences between sample grade-distributions. Two forms of the test are used: a one-tailed test and a two-tailed test. For both tests, $\chi^{2}=4 D^{2 *}\left(\left(n_{1} n_{2}\right) /\left(n_{1}+n_{2}\right)\right)$. Agreement between sample distributions is tested with two degrees of freedom and confidence levels of $\alpha=.001, .01$, or .05 for rejecting the null hypothesis.

The one-tailed test's null hypothesis is that the population distribution from which one sample is drawn does not have better grades than the other sample's population distribution. The value D is the largest difference in the predicted direction between the sample intervals' cumulative frequencies.

Students' use of video lectures is expected to make grade distributions more negatively (left) skewed. The one-tailed test appropriately measures whether one sample's grade distribution has more students with higher grades than another sample's distribution.

The two-tailed test's null hypothesis is that both of the sample distributions are random variations from the same population distribution. $\mathrm{D}$ is the largest absolute-value difference between the intervals' cumulative frequencies (Siegel, 1956, pp. 127-136).

\section{Data Collection}

This study used video lectures in an undergraduate, first-level financial accounting course in a middle-tier university's business school. The course is a requirement for all students in their first year of business study, and approximately $90-95 \%$ of the students major in a field other than the course subject.

The university is part of a 23-campus State University System in the USA. The System's mission is to teach most of the state-university students, which translates to relatively low admission requirements compared to higher tier universities. Students vary widely in education interests, academic ability, and aptitude for the course subject - from extremely good and well motivated to less capable. 
The university is located in a medium-sized metropolitan area where students live in surrounding communities and often have major interests other than university life. Many students have parttime jobs, families, and resulting time-limitations for study. Courses provide value for students when instruction and study resources are available online, whether in an online course or a classroom-course with online resources. Students can attend class as required or individually needed.

Due to very serious financial difficulties in the State, the university has substantially shrinking budgets. Offering courses with few classroom sections and one or more online sections with many "seats" is used as a way to reduce faculty cost per student. Thus, many students take a mix of classroom, classroom-online hybrid, and online courses. Video lectures are a way to extend classroom instruction quality to online learning.

\section{Sample}

Table 1 contains sample sizes and survey response rates for the with-videos and no-videos samples. Numbered column 1 gives the total number of students in each sample. Grades for these students are included in the grade distributions. Numbered columns 2 and 3 give the number and percentage of each with-video sample's students responding to the survey at the end of the course term.

Numbered columns 4 and 5 give the number and percentage of each sample's responding students who used the videos. The percentages of responding students who used the videos $(73 \%, 77.8 \%$, and $73 \%$ for video designs 1,2 , and 3 ) are significant at $\alpha=.01$ using the binomial one-sample test.

Table 1: Sample sizes and survey responses

\begin{tabular}{|c|c|c|c|c|c|}
\hline Sample & $\begin{array}{c}(1) \\
\# \\
\text { Students } \\
\text { in } \\
\text { sample }\end{array}$ & $\begin{array}{c}(2) \\
\# \\
\text { Survey } \\
\text { responses }\end{array}$ & $\begin{array}{c}(3)=(2) \div(1) \\
\text { Survey } \\
\text { response } \\
\text { rate } \\
(\%)\end{array}$ & $\begin{array}{c}\text { (4) } \\
\# \\
\text { Responding } \\
\text { students } \\
\text { using } \\
\text { videos }\end{array}$ & $\begin{array}{c}(5)=(4) \div(2) \\
\% \\
\text { Responding } \\
\text { students } \\
\text { using } \\
\text { videos }\end{array}$ \\
\hline $\begin{array}{c}\text { Video } \\
\text { design } 1 \\
\text { (three course } \\
\text { sections) }\end{array}$ & 132 & 74 & 56 & 54 & 73 \\
\hline $\begin{array}{c}\text { Video } \\
\text { design } 2 \\
\text { (two course } \\
\text { sections) }\end{array}$ & 79 & 54 & 68 & 42 & 77.8 \\
\hline $\begin{array}{c}\text { Video } \\
\text { design } 3 \\
\text { (three course } \\
\text { sections) }\end{array}$ & 137 & 74 & 54 & 54 & 73 \\
\hline $\begin{array}{l}\text { No-videos } \\
\text { sample } \\
\text { (one course } \\
\text { section) }\end{array}$ & 33 & & & & \\
\hline
\end{tabular}




\section{Bias}

Three areas of possible bias are sampling bias, survey response bias, and survey non-response bias. Sampling bias is relevant to grade distribution analysis for the with-videos and no-videos samples. Response and non-response bias are relevant to survey response evaluation for the withvideos samples.

\section{Sampling bias}

It cannot be demonstrated that the samples are free of major differences in student characteristics. Given the student and academic-environment characteristics, one or two standard factors such as student scores on college admission tests or grade point averages do not capture all influences on students' study needs, attitudes, or performance.

Instead, the likelihood of significant sampling bias is evaluated in terms of how the samples were constructed. Bias was minimized by random selection and the following structural characteristics.

Each sample section's enrollment was drawn from the course's total business-school enrollment in a single course term. More course sections were available than those in this study's samples. Students chose the section in which they enrolled.

The 2-3 class sections in each with-videos sample met at different times and on different days. Each of these samples was large enough (Table 1, numbered column 1) to contain students with varied backgrounds, capabilities, and reasons for enrolling. They were not disproportionately made up of students with a single time or class-day need, or related characteristic such as working part-time.

The no-videos sample has the most risk of an unrepresentative student-mix since it was made up of one class section and had a relatively small size (33 students). Otherwise, the no-videos sample was drawn by the same process as the other samples. The sample size is not too small for statistical analysis.

Generally, students did not have information about pedagogy to influence their enrollment choice. The course is a requirement at the beginning of students' business studies, students are new to the business school, and approximately one-third of the students come from two-year community colleges. The sample sections were not advertised in university course descriptions as computer enhanced.

New students do not have access to a network of students who can inform them about the types and value of the course's instruction methods. Evaluations of instructors that are available online tend to focus on student comments about instructor difficulty and classroom-lecture clarity.

All videos were available to all students in each with-videos course section. The videos could be easily accessed from any personal computer, including those in on-campus computer labs.

\section{Survey response bias}

For survey responses, several factors focused students on accurately reporting their experience with the videos, and inhibited response-bias.

Each video design was tested in a separate course term with a different sample of students. Therefore, students across these samples were not able to exchange information about different video designs. They did not have information to form a preference among designs and alter their responses from their actual experience.

There was a different video design for each sample, but otherwise, all class sections in all of these samples had the same instructor and instruction methods. The same topics were taught in all sec- 
tions, and all exam questions had similar subject coverage, difficulty, and grading weight. Performance comparisons reflect only video design differences.

Since each with-videos sample was made up of 2-3 class sections, a "group think" or single view of a video design could not develop across all students in a sample.

Surveys were returned by students anonymously and response was voluntary. In addition, the instructor presented the videos as available if helpful. Alternative study resources were always available, and students were told to use whichever resources best helped them learn. Thus, the students had no information about an instructor-preferred answer - information that could bias their survey responses.

\section{Survey non-response bias}

Non-response bias involves whether survey responses reflect opinions for all students in a sample or only opinions of responding students. Students were asked to respond so that any changes they thought were needed in the videos could be identified and made to help future students. This motivation sought to increase the response rate and promote truthful responses.

Two possible cases could have caused non-response bias. First, some students not responding to the survey may have used the videos, thought they had little value, and not taken the time to respond. It is unlikely that a significant number of students would do this and not respond to at least a few questions to register their assessment.

For example, many students responded by only checking questions 3-5 - saying that they did not use the videos. Asked to fill out the survey to help with revisions for future students, nonresponse implies a disregard for helping fellow students. In addition, response took little effort and time. The survey was on one-side of a single page, had 21 short questions, and required only a "yes" or "no" check mark to answer. Response to the entire survey required less than 10 minutes.

Second, students may not have responded because they did not use the videos and had no informed opinion. This case does not reduce a primary value of most survey questions, which was discovery of areas where video lectures help students who use them.

\section{Results}

The instruction sequence in the course was classroom lecture of a text chapter, labs covering major quantitative problems in the chapter, and then a midterm exam covering 3-4 chapters. Group participation and significant grade weight for lab problems gave students incentive to prepare for the labs by beginning to learn problem methods and related concepts.

\section{Initial Learning and Midterm Exam Review}

This initial learning occurred 1-4 weeks before students began review for the midterm exam. Thus, survey questions were able to distinguish between student use of videos lectures for initial learning and for midterm exam preparation. Table 2 summarizes the survey responses in these areas.

The students view all three video designs as significantly helpful for both initial learning and midterm exam review. Significance is at $\alpha=.01$ using the binomial one-sample test, except for design 2 exam review with significance at $\alpha=.05$. This helpfulness is regardless of the video's design, and the students recognized it apart from help received from the alternative study resources. 
Design 2's strong relief elements are the only significant difference between designs 2 and 3 . Design 3 has subtle relief elements. Comparing the designs' Table 2 percentages for initial learning, this difference explains design 2's substantially better performance (83.3\% compared to $71.7 \%)$.

Comparing designs 2 and 3 for exam review, design 2's 61.5\% underperforms design 3's 70.6\%. This is explained by many students' not wanting to view the design 2 videos again because of their frustration with its strongly presented relief elements. Even so, design 2's percentage is statistically significant.

Comparing design 3 and 1's percentages, they are approximately equal for both initial learning and exam review. This indicates that design 3's improvements in content formats, topicdevelopment techniques, production values, and subtle relief elements did not translate to helpfulness for significantly more students.

Comparing design 2 and 1's initial-learning percentages, design 2 significantly outperforms design 1 (83.3\% compared to $68.5 \%)$. For initial learning, design 2's strongly presented relief elements are the cause of it outperforming design 3. Designs 3 and 1's percentages are approximately equal. It follows that design 2 's strongly presented relief elements explain why it outperformed design 1 .

Comparing design 2 and 1's percentages for exam review, as with the design 2 and 3 exam-review comparison, design 2's underperformance is attributable to many students not wanting to view the videos again after having viewed them for initial learning and being frustrated by their strong presentation of relief elements.

Generalizing the above observations, they indicate that an intensity level in presenting relief elements must be exceeded for a video design to improve initial learning by a maximum amount. Design 3's subtle presentation does not perform significantly better than design 1's lack of relief elements.

Table 2: Survey "yes" response rates (\%) for videos' helpfulness in initial learning and exam review

\begin{tabular}{lccc}
\hline \multicolumn{1}{c}{ Survey Question } & $\begin{array}{c}\text { Video } \\
\text { design } \\
\mathbf{1}\end{array}$ & $\begin{array}{c}\text { Video } \\
\text { design } \\
\mathbf{2}\end{array}$ & $\begin{array}{c}\text { Video } \\
\text { design } \\
\mathbf{3}\end{array}$ \\
\hline $\begin{array}{l}\text { Did videos help understand the classroom lecture } \\
\text { presentation of concepts and problems? }\end{array}$ & 68.5 & 83.3 & 71.7 \\
\begin{tabular}{l} 
Did the videos help prepare for midterm exams? \\
\hline
\end{tabular}
\end{tabular}

\section{Learning with Different Types of Topic Difficulty}

Learning the course's subject involves two types of topic difficulty - type 1 and type 2 . In type 1 learning, the subject is quantitative, technically complex, and involves a large-scale problem that has a unifying focus. In this study's course, many students have difficulty with this type of material because they are majoring in disciplines other than the course subject and have low interest and no work background or previous learning experience in the subject.

Type 2 learning involves a large mass of facts with no single, unifying focus, i.e., a large number and variety of concepts, professional rules, and terminology. A few small problem-methods must be learned, but they involve a smaller scale of complexity and are much less difficult than in type 1 learning. 


\section{Type 1 learning using video lectures}

Type 1 learning is the focus in the first course segment through the first midterm exam. Figure 1 shows the first-exam grade distributions for the three video-design samples. Each column position represents a sample, and viewing that column from left to right across the grade ranges $(0$ $50 \%, 50-60 \%, \ldots)$ shows the grade distribution for the sample. Figure 1's underlying percentages are shown in Table 3.

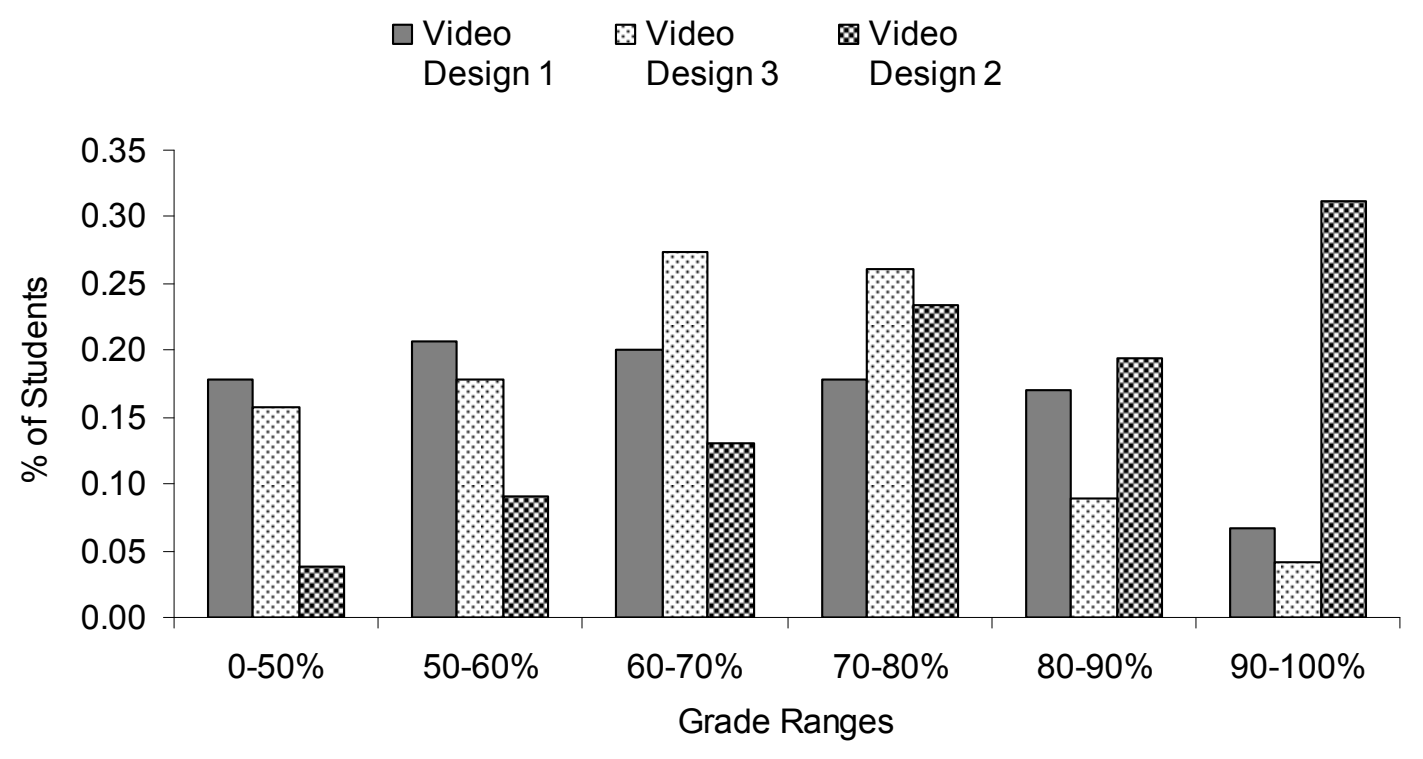

Figure 1: Type 1 Learning - 1st Midterm Exam Grade Distributions

Observationally, video design 2 has fewer grades in the $0-70 \%$ ranges and more grades in the 90 $100 \%$ range than designs 1 and 3. Using the Kolmogorov-Smirnov one-tailed test, design 2's grade distribution is better than design 1 and 3's distributions at $\alpha=.001$.

Design 2 performs best in helping underachieving students move to higher grade-ranges and more-capable students achieve command of the subject. Using reasoning previously developed, this is attributable to design 2's strongly presented relief elements.

Comparing design 3 to design 1, no consistent pattern of superiority is observed. Using the onetailed test, design 3 is not better than design 1 at $\alpha=.05$. Using the two-tailed test, the null hypothesis is not rejected that designs 3 and 1 have grade distributions from the same population, and the rejection Type I risk is $\alpha>.20$. These performance results occur even though design 3 was thought to have substantial design improvements compared to design 1. 
Table 3: Types 1 and 2 learning: percentages (\%) of students in grade distributions for video and no-videos samples

\begin{tabular}{|c|c|c|c|c|c|c|c|c|c|c|c|c|}
\hline \multirow[b]{2}{*}{$\begin{array}{l}\text { Grade } \\
\text { range }\end{array}$} & \multicolumn{4}{|c|}{ Type 1, Exam 1} & \multicolumn{4}{|c|}{ Type 2, exam 2} & \multicolumn{4}{|c|}{ Type 2, exam 3} \\
\hline & $\begin{array}{c}\text { No } \\
\text { videos }\end{array}$ & $\begin{array}{c}\text { Video } \\
\text { design } \\
1\end{array}$ & $\begin{array}{c}\text { Video } \\
\text { design } \\
\mathbf{3}\end{array}$ & $\begin{array}{c}\text { Video } \\
\text { design } \\
2\end{array}$ & $\begin{array}{c}\text { No } \\
\text { videos }\end{array}$ & $\begin{array}{c}\text { Video } \\
\text { design } \\
1\end{array}$ & $\begin{array}{c}\text { Video } \\
\text { design } \\
\mathbf{3}\end{array}$ & $\begin{array}{c}\text { Video } \\
\text { design } \\
2\end{array}$ & $\begin{array}{c}\text { No } \\
\text { videos }\end{array}$ & $\begin{array}{c}\text { Video } \\
\text { design } \\
1\end{array}$ & $\begin{array}{c}\text { Video } \\
\text { design } \\
\mathbf{3}\end{array}$ & $\begin{array}{c}\text { Video } \\
\text { design } \\
2\end{array}$ \\
\hline $0-50$ & 5 & 21 & 17 & 4 & 13 & 13 & 12 & 4 & 24 & 19 & 19 & 1 \\
\hline $50-60$ & 25 & 20 & 18 & 9 & 31 & 9 & 3 & 3 & 7 & 10 & 9 & 3 \\
\hline $60-70$ & 25 & 19 & 27 & 13 & 22 & 6 & 12 & 1 & 28 & 13 & 9 & 9 \\
\hline $70-80$ & 20 & 17 & 26 & 23 & 19 & 11 & 18 & 14 & 17 & 19 & 15 & 5 \\
\hline $80-90$ & 20 & 16 & 9 & 19 & 09 & 22 & 22 & 13 & 14 & 19 & 25 & 19 \\
\hline $90-100$ & 5 & 6 & 4 & 31 & 6 & 39 & 33 & 65 & 10 & 20 & 23 & 63 \\
\hline
\end{tabular}

\section{Type 2 learning using video lectures}

Type 2 learning is the focus in the second and third (last) course segments, with each segment having a midterm exam. Figures 2 and 3 show the second and third exam distributions for the with-video samples. The underlying percentages are shown in Table 3.

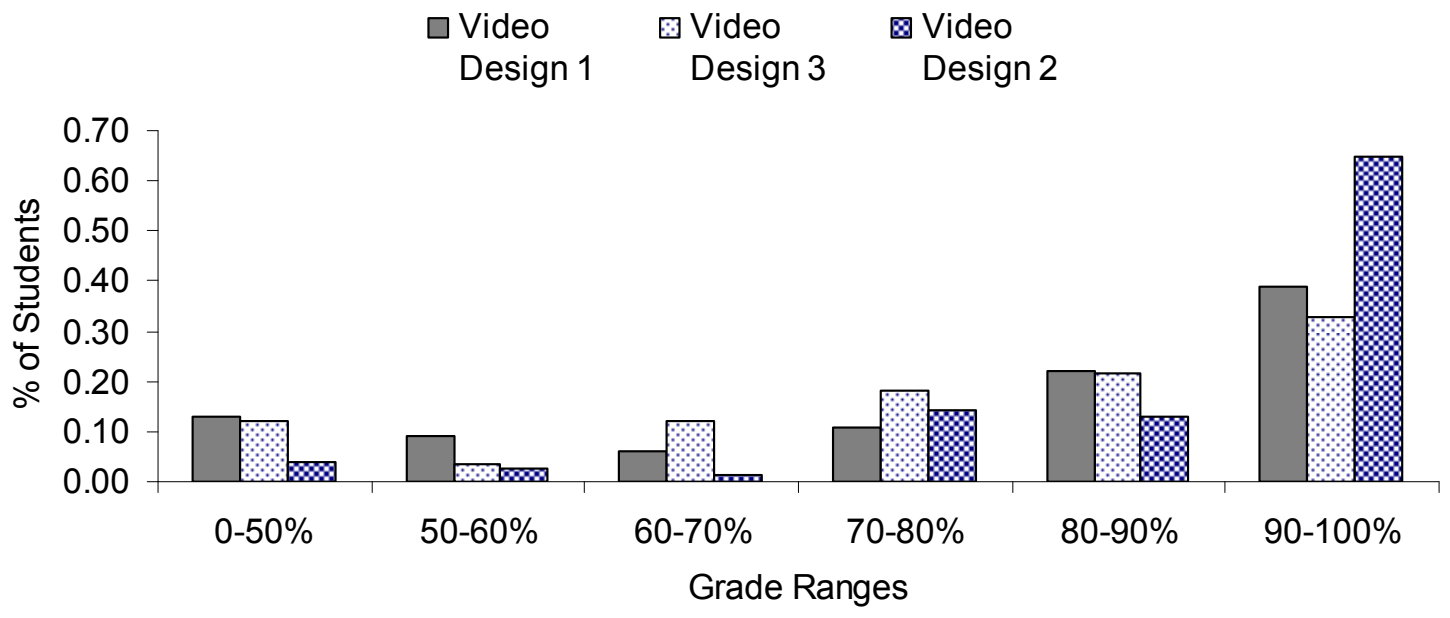

Figure 2: Type 2 Learning - 2nd Midterm Exam Grade Distributions 


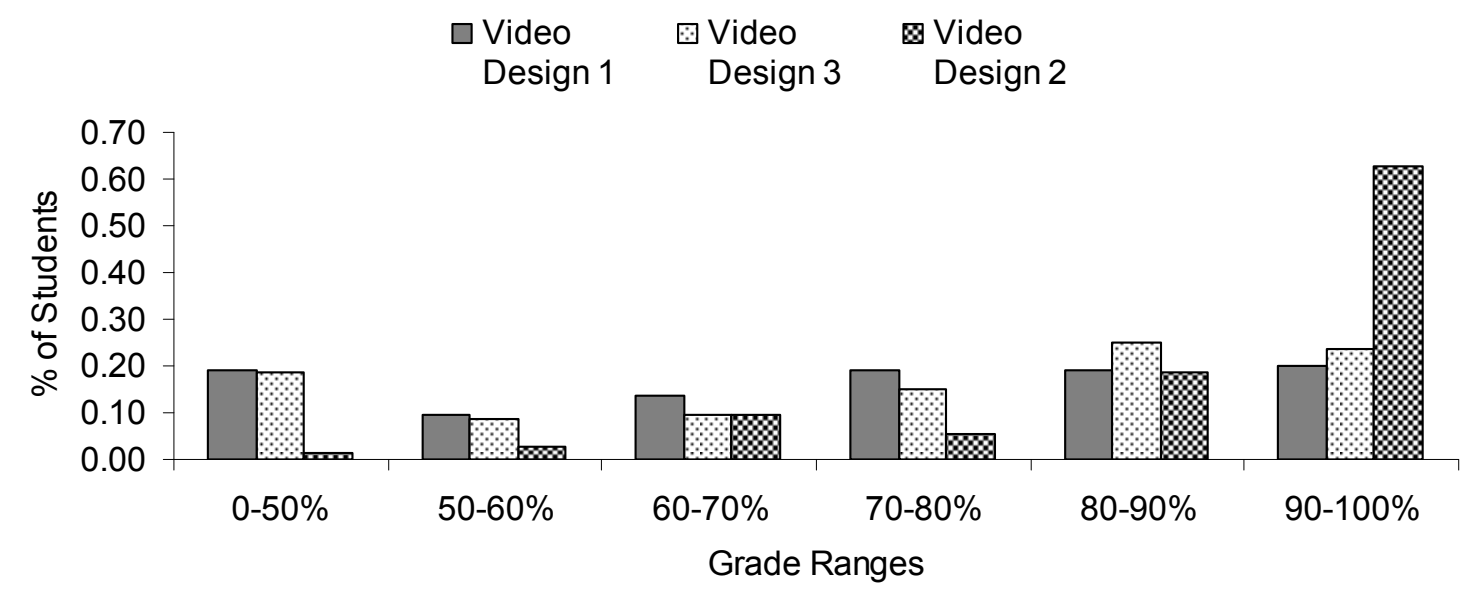

Figure 3: Type 2 Learning - 3rd Midterm Exam Grade Distributions

Observationally for exams 2 and 3, design 2 has fewer low grades and more high grades than designs 1 and 3. Using the Kolmogorov-Smirnov one-tailed test for exam 2, design 2's grade distribution is better than design 1 and 3's distributions at $\alpha=.05$. For exam 3, design 2's distribution is better than design 1's distribution at $\alpha=.001$ and than design 3's distribution at $\alpha=.01$. As with type-1 learning, design 2's strong relief elements explain its superiority.

Comparing design 3 to design 1, no design 3 superiority is observed for exams 2 and 3 . The onetailed test shows that design 3's grade distributions are not significantly better than design 1's distributions at $\alpha=.05$. Using the two-tailed test, the null hypothesis is not rejected that designs 3 and 1 have sample distributions from the same population. The two-tailed test's rejection Type I risk is $\alpha>.20$.

\section{With-videos and no-videos comparisons}

Table 3 contains the grade distribution percentages for the no-videos sample as well as the percentages underlying Figures 1, 2, and 3.

For design 2's performance, its exam 1 percentages are significantly better than the no-videos distribution at $\alpha=.05$ using the Kolmogorov-Smirnov one-tailed test. For exams 2 and 3, design 2's distributions are significantly better at $\alpha=.001$.

For design 1 and 3's performance compared to the no-videos distributions, the results are mixed and inconclusive. For exam 2 and the one-tailed test, designs 1 and 3 are better than the no-videos distribution at $\alpha=.001$. However, for exams 1 and 3, designs 1 and 3 are not better at $\alpha=.05$.

Using the two-tailed test, the null hypothesis is not rejected that the design 1 and 3 and no-videos distributions are drawn from the same population. For the exam 1 comparisons, the rejection Type I risk is $\alpha>.20$. For exam 3, the rejection Type I risk is $\alpha>.20$ for the design 1, no-videos comparison and $\alpha>.05$ for the design 3, no-videos comparison.

\section{Tutoring}

As unique tutorial aids, video lectures have the authoritative quality of explanations given by the course instructor as opposed to explanations from students in a campus tutoring-lab. Their pointsto-be-learned emphases are consistent with what is said in the classroom, and they continue the student-instructor rapport and thought patterns established in the classroom. 
Surveyed students said that video lectures provide tutoring help. Favorable response percentages of $63 \%, 78.6 \%$, and $67.9 \%$ for designs 1,2 , and 3 are statistically significant using the binomial one-sample test at confidence levels of $\alpha=.05, .01$, and .01, respectively.

Design 2 has the highest percentage, while designs 1 and 3 have lower percentages that are close together. Following logic previously discussed, these results are explained by design 2's strongly presented relief elements. The data indicate that a more "fun" learning environment yields a helpful tutoring effect for more students.

When students were asked if the videos made learning easier, a similar response pattern occurred $(35 \%, 71 \%$, and $50 \%$ for designs 1,2 , and 3$)$. Design 2 's percentage is statistically significant at $\alpha$ $=.01$, and design 1 and 3's percentages are not significant at $\alpha=.05$. Again, a more "fun" learning environment influences students' perception of the learning process.

\section{Course Dropout Rates}

Improving the learning process for at-risk students is important to achieve lower dropout rates. Successful retention at the course level requires that students believe they can learn the material and succeed on exams. This requires a positive early-experience with the course's instruction methods and exams, before students develop an expectation of failure.

Dropout rates are computed for students who took the first exam and dropped the course before the second exam (a period of about a month). The first course segment through the first midterm exam has the most difficult problem material and creates the course's greatest learning frustration. The number of dropouts soon after the first exam is at the highest level for any segment of the course.

All with-videos samples had significantly lower dropout rates than the no-videos sample at $\alpha=$ .01 using the binomial one-sample test. For video designs 1, 2, and 3, the dropout rates were $4.4 \%, 0 \%$ (no dropouts), and $3.4 \%$. The no-videos dropout rate was $11.1 \%$. This improvement is most likely due to the tutoring value of the video lectures (as opposed to, for example, a learning style preference).

\section{Final Exam Review}

Figure 4 shows the final exam grade-distributions for the with-videos samples. Table 4 tabulates Figure 4's underlying percentages, and adds the no-videos distribution percentages. Observationally and with the Kolmogorov-Smirnov one-tailed test at $\alpha=.05$, no with-videos distribution is better than the other with-videos distributions. Only the design 3 distribution is significantly better than the no-videos distribution.

The design 1 and 2 results are inconsistent with expectations where all with-videos distributions were expected to be significantly better than the no-videos distribution. Being comprehensive, the final exam required extensive preparation; and since it was optional, students only took it to improve their course grade.

It was expected that students who had underachieved their grade expectations on the midterm exams would take advantage of the videos for efficient, structured learning for the final exam. Because it was not feasible to survey students at the beginning of the final exam or as they left at different times, there are no data to explain the design 1 and 2 results. 


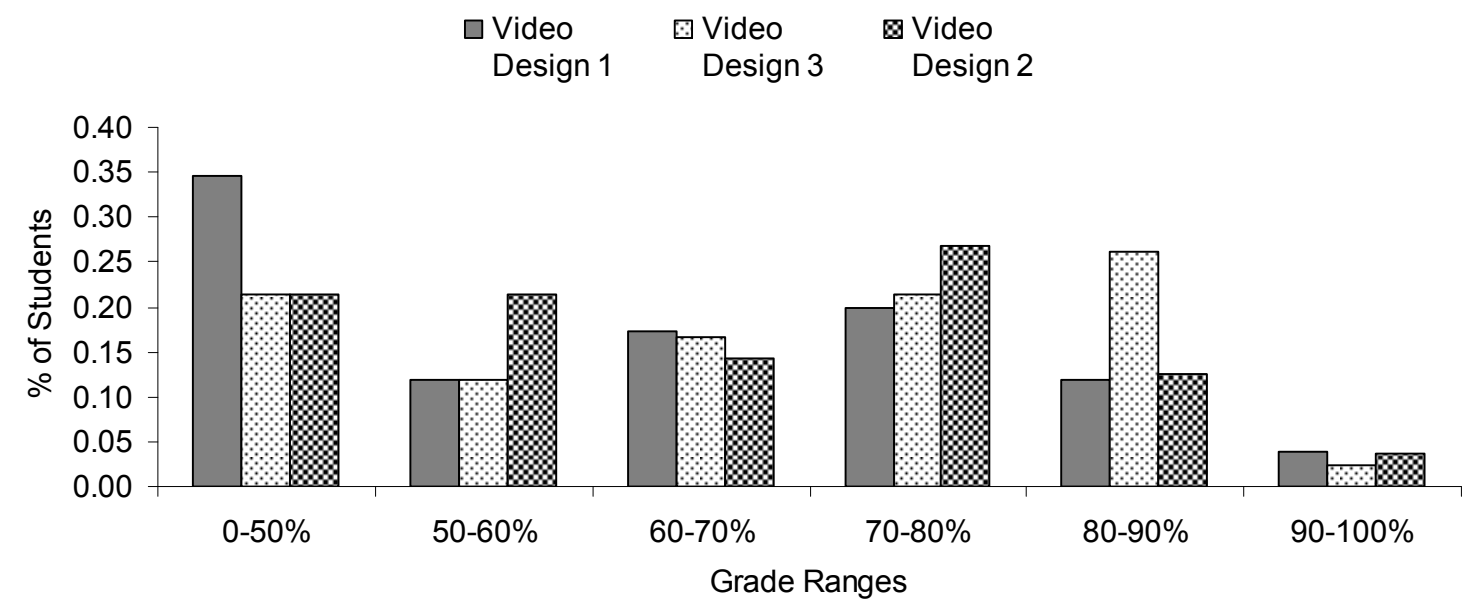

Figure 4: Optional, Comprehensive Final Exam Grade Distributions

Table 4: Percentages $(\%)$ of students in the final exam grade ranges

\begin{tabular}{ccccc}
\hline $\begin{array}{c}\text { Grade } \\
\text { range }\end{array}$ & $\begin{array}{c}\text { No } \\
\text { videos }\end{array}$ & $\begin{array}{c}\text { Video } \\
\text { design } \\
\mathbf{1}\end{array}$ & $\begin{array}{c}\text { Video } \\
\text { design }\end{array}$ & $\begin{array}{c}\text { Video } \\
\text { design }\end{array}$ \\
\hline $0-50$ & 48 & 35 & 21 & 21 \\
$50-60$ & 14 & 12 & 12 & 21 \\
$60-70$ & 24 & 17 & 17 & 14 \\
$70-80$ & 14 & 20 & 21 & 27 \\
$80-90$ & 0 & 12 & 26 & 13 \\
$90-100$ & 0 & 4 & 2 & 4 \\
\hline
\end{tabular}

\section{Course Grades}

Figure 5 shows adjusted course grade distributions for the with-videos samples. The percentages underlying Figure 5 and the no-videos distribution percentages are tabulated in Table 5.

Adjusted grades are computed as the final course grades students received minus homework and lab practice-problem grades. This removes the curve effects of effort-focused and liberally graded homework and lab practice-problems. Adjusted course grades reflect only midterm and final exam performance. 

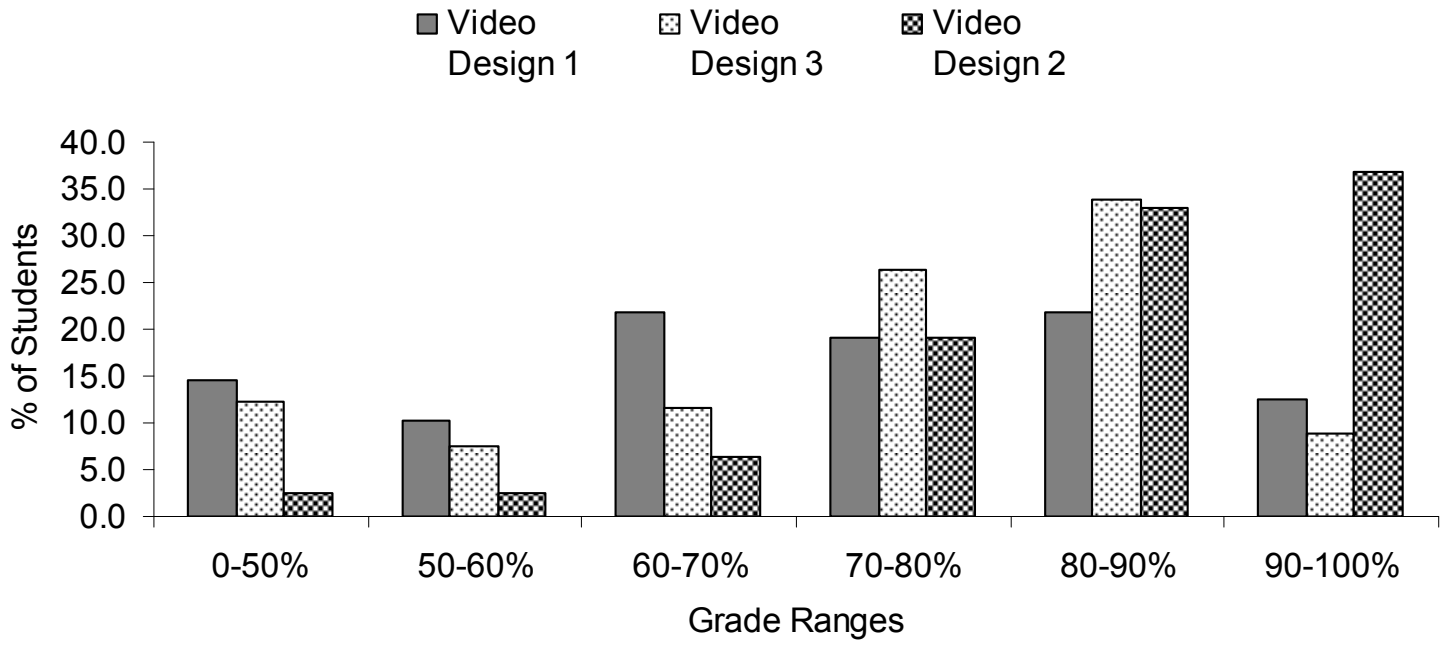

Figure 5: Adjusted Course Grade Distributions

Observing the Figure 5 distributions, fewer grades are in the $0-70 \%$ grade ranges and more are in the higher ranges for design 2 compared to design 3, and for designs 2 and 3 compared to design 1. The Kolmogorov-Smirnov one-tailed test confirms these observations with the design 2 distribution being significantly better than design 3 at $\alpha=.05$, and the design 2 and 3 distributions being better than design 1 at $\alpha=.001$ and $\alpha=.05$.

Using the one-tailed test to compare the with-videos distributions to the no-videos distribution, the design 2 and 3 distributions are significantly better than the no-videos distribution at $\alpha=.001$ and $\alpha=.05$. Design 1 has no significant difference from the no-videos distribution.

As in other areas of this study, design 2's learning environment with strongly presented relief elements yields the greatest benefit.

Table 5: Adjusted-course-grade distribution percentages (\%) for no-videos and with-videos samples

\begin{tabular}{ccccc}
\hline $\begin{array}{c}\text { Grade } \\
\text { range }\end{array}$ & $\begin{array}{c}\text { No } \\
\text { videos }\end{array}$ & $\begin{array}{c}\text { Video } \\
\text { design } \\
\mathbf{1}\end{array}$ & $\begin{array}{c}\text { Video } \\
\text { design } \\
\mathbf{3}\end{array}$ & $\begin{array}{c}\text { Video } \\
\text { design }\end{array}$ \\
\hline $0-50$ & 8.1 & 14.6 & 12.2 & 2.5 \\
$50-60$ & 29.7 & 10.2 & 7.4 & 2.5 \\
$60-70$ & 18.9 & 21.9 & 11.5 & 6.3 \\
$70-80$ & 32.4 & 19.0 & 26.4 & 19.0 \\
$80-90$ & 8.1 & 21.9 & 33.8 & 32.9 \\
$90-100$ & 2.7 & 12.4 & 8.8 & 36.7 \\
\hline
\end{tabular}




\section{Advantages, Difficulties, and Limitations}

Additional comments on advantages, difficulties, and limitations in using video lectures are made below. They involve appropriate applications of video lectures and the production and distribution of videos.

First, this study addresses video-use in an introductory, lower-division course that has a mix of basic concepts and technical skills. The course has no coverage of decision-making or how to formulate models to fit case situations. It is difficult to imagine a disadvantage to students from making video lectures available for voluntary use with this type of material. They provide tutorial support even if only for a small number of high-risk students.

From an academic program perspective, the videos may extend the course's viability to students in other academic disciplines where typical abilities do not support easy success in the course discipline. For example, a student majoring in chemistry may want to take an accounting course to develop some capability for an administrative career in chemistry. A tutoring resource may make this feasible.

Second, the video lectures may be interwoven with other instruction methods or they may be used as free-standing tutorial support. In the current study, videos support every classroom lecture and are valuable in helping students prepare for labs that occur very quickly following the classroom lecture. In an upper-division course, video lectures could be available only for the most difficult course topics and a few background topics that students should have previously studied as prerequisites for the course.

Third, the instructor's personal cost in time and effort seems minimal since there is inexpensive commercial software available that is designed for mass-market usability. Such software supports pausing and then continuing a video while it is being recorded and offers post-recording editing. Only a few of the software's features are needed to produce video lectures.

For an early-development stage of the current study, the author and a co-author more fully explain video-lecture production details (Brecht \& Ogilby, 2008). Currently, the author is using Debut Video Capture, which costs about 50 USD (http://www.nchsoftware.com/capture).

Of course, if the user has extensive difficulty with using computers and software, support is needed from the user's university technical-support staff. However, substantial help should be needed only in producing the first video. At most, ongoing help should be needed only occasionally. The content of videos changes, but not the process of using the software to produce a video.

Fourth, some instructors may be hesitant to allocate their time to developing video lectures and integrating them into a course. This may be a particularly difficult issue when teaching-oriented or technological activities are not rewarded by the school or the social culture of the school.

Shamir-Inbal, Dayan, and Kali (2009) discuss this issue and pose the introduction of technology into a school culture as requiring a life-cycle perspective. They found that this perspective yields substantial and sustainable success in assimilating technology and online instruction. The assimilation model they propose uses mentoring and a gradual building of resources and social support.

Fifth, a university's capacity to store large video files and to stream (play) videos online may be limited. In this study, a public university provided the instructor's website with effectively unlimited memory for the videos. The university has the capacity to stream the videos for student internet viewing on demand. There was no budget cost to the instructor's college or academic department, and no external funding was required.

If these university resources are not available, YouTube (http://www.youtube.com) may offer a suitable option for online video play. Currently, YouTube videos are free to upload or view, al- 
though there has been much discussion on the internet about use-charges as a way to increase YouTube's revenues (search Google: "YouTube charges to users"). For an example of the use of YouTube video distribution for a university course, see Teaching Center (2011).

Each video on YouTube may be up to fifteen minutes in length with no restriction on the number of videos. Longer lengths are possible under restrictive conditions. More information is available at http://support.google.com/youtube/bin/answer.py?hl=en\&answer=71673. Google is the parent company of YouTube.

Additionally, the Khan Academy (http://www.khanacademy.org) creates educational videos that can be viewed to see how its website both hosts video lectures and has links to them through YouTube. Further, the website's videos can be viewed to obtain examples of a video lecture style similar to the one used in this study. The only instructor presence is the audio lecture, and only topic content is viewed on the screen. Kaplan (2010) highlights the value of this type of video lecture with the following comment.

"His low-tech, conversational tutorials -- Khan's face never appears, and viewers see only his unadorned step-by-step doodles and diagrams on an electronic blackboard -- are more than merely another example of viral media distributed at negligible cost to the universe. Khan Academy holds the promise of a virtual school: an educational transformation that de-emphasizes classrooms, campus and administrative infrastructure, and even brand-name instructors."

Sixth, video lectures may be inadvisable when they enable student behaviour that undermines attention to the unique learning objectives of other instruction methods. For example, students may not attend classroom sessions, but instead rely on the videos to learn what they believe is needed to succeed in the course.

However, in advanced studies, skills in problem formulation and complex decision-making may not be teachable in a lecture without discussion. Participation in discussions may be necessary to learn how to apply discipline principles to finely-differentiated situation facts.

\section{Conclusions}

This study measures learning benefits from voluntarily used instructional videos that supplement classroom lectures. The course was in an in-residence, classroom course. The video lectures were prepared by the course instructor and have the same content as the classroom lectures, but are delivered at a slower, more step-by-step pace. A statistically significant number of surveyed students assessed the videos as a helpful tutoring resource.

Video lectures give students control of the lecture and are portable. Students can replay segments and stop the lecture as they study to understand the content. They can skip topic segments they understand. In effect, they can adjust the instructor's delivery speed and topic selection to match their individual learning pace and interests. They can view the lecture when and where they study most effectively.

Three video designs were tested, each with a different learning environment. Videos with a strong presentation of relief and change-of-pace elements (design 2's use of graphics and sounds) are the most learning-effective. This suggests that student attentiveness and engagement in studying is sensitive to the videos' learning environment.

Design 2's superior performance (compared to designs 1 and 3 and the no-videos sample) occurs throughout the study. Survey data show that design 2's students had the highest rates of video-use. Survey data also indicate that design 2's initial-learning helpfulness was dominantly better than the helpfulness of designs 1 and 3 and when no videos were available. 
For two types of learning difficulty, grade distributions indicate that design 2's midterm-exam grades are consistently better than the design 1 and 3 and no-videos grades. Significant percentages of survey responses credit all video designs with providing tutoring support, where design 2 has the highest percentage effect. Additionally, responses credited design 2 with the only significant effect in making learning easier.

All video designs significantly reduce course dropout rates compared to not having video lectures available. Design 2 had the lowest dropout rate with no dropouts. Design 2's course grade distribution (adjusted to remove grade-curving effects) is significantly better that the distributions for the other video designs and the no-videos sample.

\section{References}

Active Learning Online Team. (2011). What is active learning? The Abilene Christian University Adams Center for Teaching Excellence [Active Learning Online]. Retrieved from http://www.acu.edu/cte/activelearning/focus.htm

Adler, R. W., \& Milne, M. J. (1995). Increasing learner-control and reflection: Towards learning-to-learn in an undergraduate management accounting course. Accounting Education, 4(2), 105-119.

Brecht, H. D., \& Ogilby, S. M. (2008). Enabling a comprehensive teaching strategy: Video lectures. Journal of Information Technology Education: Innovations in Practice, 7, 71-86. Retrieved from http://www.jite.org/documents/Vol7/JITEV7IIP071-086Brecht371.pdf

Bryant, S. M., \& Hunton, J. E. (2000). The use of technology in the delivery of instruction: Implications for accounting educators and education researchers. Issues in Accounting Education, 15(1), 129-162.

Etter, E. R., Burmeister, S. L., \& Elder, R. J. (2000). Improving student performance and retention via supplemental instruction. Journal of Accounting Education, 18(4), 355-368.

Geri, N. (2012). The resonance factor: Probing the impact of video on student retention in distance learning. Interdisciplinary Journal of E-Learning and Learning Objects, 8, 1-13. Retrieved from http://www.ijello.org/Volume8/IJELLOv8p001-013Geri0794.pdf

Habley, W. R., \& McClanahan, R. (2004). What works best in student retention - All survey colleges (ACT, Inc. Information for Life Transitions). Retrieved from http://www.act.org/research/policymakers/pdf/droptables/FourYearPublic.pdf

Jones, J. P., \& Fields, K. T. (2001). The role of supplemental instruction in the first accounting course. Issues in Accounting Education, 16(4), 531-547.

Kalyuga, S. (2009). Knowledge elaboration: A cognitive load perspective. Learning and Instruction, 19, 402-410. Retrieved from http://202.116.45.198/xxjy/xxjy2/content/wenjian/ckwx/y/6/2.pdf

Kaplan, D. A. (August 24, 2010). Innovation in education: Bill Gates' favorite teacher. CNN Money. Retrieved from http://money.cnn.com/2010/08/23/technology/sal_khan_academy.fortune/index.htm

Kirschner, P. A. (2002). Cognitive load theory: Implications of cognitive load theory on the design of learning. Learning and Instruction, 12, 1-10. Retrieved from http://www.sciencedirect.com/science/article/pii/S0959475201000147

Lesser, L. M., \& Pearl, D. K. (2008). Functional fun in statistics teaching: Resources, research and recommendations. Journal of Statistics Education, 16(3), 1-9. Retrieved from http://www.amstat.org/publications/jse/v16n3/lesser.pdf

Lewis, K. R. (2010, October 28). High college dropout rate threatens U.S. growth. The Fiscal Times. Retrieved from http://www.thefiscaltimes.com/Articles/2010/10/28/High-College-Dropout-RateThreatens-US-Growth.aspx\#page1

Mabey, C., Topham, P., \& Kaye, G. R. (1998). Computer-based courseware: A comparative review of the learner's experience. Accounting Education, 7(1), 51-64. 
Mahoney, L. S., \& Dziuban, C. (2000). Assessing web-enhanced courses and student learning outcomes. Accounting Educators' Journal, 12, 1-14. Retrieved from http://www.aejournal.com/ojs/index.php/aej/article/viewFile/18/18

Martin, D. C., Arendale, D. R., \& Blanc, R. (1997). Mainstreaming of developmental education: Supplemental instruction and video-based supplemental instruction. Unpublished Manuscript, National Center for Supplemental Instruction, University of Missouri-Kansas City, Kansas City, Missouri. Retrieved from http://a.web.umkc.edu/arendaled/mainstreamDE97.pdf

Mayer, R. E., \& Moreno, R. (2003). Nine ways to reduce cognitive load in multimedia learning. Educational Psychologist, 38(1), 43-52. Retrieved from http://www.elizabethoc.com/9ways/article.pdf

Merrill, D. C., Reiser, B. J., Ranney, M., \& Trafton, J. G. (1992). Effective tutoring techniques: A comparison of human tutors and intelligent tutoring systems. The Journal of the Learning Sciences, 2(3), $277-$ 305. Retrieved from http://www.cs.pitt.edu/ chopin/references/tig/effective tutoring.pdf

Moreno, R. (2006). Learning in high-tech and multimedia environments. Current Directions in Psychological Science, 15(2), 63-67. Retrieved from http://cdp.sagepub.com/content/15/2/63.full.pdf $+\mathrm{html}$

Nemanich, L., Banks, M., \& Vera, D. (2009). Enhancing knowledge transfer in classroom versus online settings: The interplay among instructor, student, content, and context. Decision Sciences Journal of Innovative Education, 7(1), 123-148. Retrieved from http://onlinelibrary.wiley.com/doi/10.1111/j.1540-4609.2008.00208.x/pdf

Nicholson, J., Nicholson, D., \& Valacich, J. S. (2008). Examining the effects of technology attributes on learning: a contingency perspective. Journal of Information Technology Education, 7, 185-204. Retrieved from http://www.jite.org/documents/Vol7/JITEv7p185-204Nicholson364.pdf

Office of Minority Student Affairs. (2010). Academic services \& programs: Tutoring and study skills workshops [Academic services notice]. Retrieved from http://www.omsa.uiuc.edu/academics/tutoring.html

Phelps, J. M., \& Evans, R. (2006). Supplemental instruction in developmental mathematics. Community College Enterprise, 12(1), 21-37. Retrieved from http://www.schoolcraft.edu/pdfs/cce/12.1.21-37.pdf

Rosenshine, B., \& Meister, C. (1992). The use of scaffolds for teaching higher-level cognitive strategies. Educational Leadership, 49(7), 26-33. Retrieved from http://www.ascd.org/ASCD/pdf/journals/ed_lead/el_199204_rosenshine.pdf

Shamir-Inbal, T., Dayan, J., \& Kali, Y. (2009). Assimilating online technologies into school culture. Interdisciplinary Journal of E-Learning and Learning Objects, 5, 307-334. Retrieved from http://www.ijello.org/Volume5/IJELLOv5p307-334Samir-Inbal675.pdf

Siegel, S. (1956). Nonparametric statistics for the behavioral sciences. New York, New York: McGrawHill.

Simpson, N. (2006). Asynchronous access to conventional course delivery: A pilot project. British Journal of Educational Technology, 37(4), 527-537.

Sweller, J. (1988). Cognitive load during problem solving: Effects on learning. Cognitive Science, 12, 257285. Retrieved from http://csjarchive.cogsci.rpi.edu/1988v12/i02/p0257p0285/main.pdf

Sweller, J., \& Cooper, G. A. (1985). The use of worked examples as a substitute for problem solving in learning algebra. Cognition and Instruction, 2(1), 59-89.

Teaching Center. (2011, April 26). Video supplemental instruction. University of Florida: Academic Technology. Retrieved from https://teachingcenter.ufl.edu/vsi/mac2233/final exam.html

Van Wyk, M. M. (2011). The use of cartoons as a teaching tool to enhance student learning in economics education. Journal of Social Science, 26(2), 117-130. Retrieved from http://www.krepublishers.com/02-Journals/JSS/JSS-26-0-000-11-Web/JSS-26-2-000-11-AbstPDF/JSS-26-2-117-11-1102-Van-Wyk-M-M/JSS-26-2-117-11-1102-Van-Wyk-M-M-Tt.pdf 


\section{Online Video Lectures}

Whatley, J., \& Ahmad, A. (2007). Using video to record summary lectures to aid students' revision. Interdisciplinary Journal of E-Learning and Learning Objects, 3, 185-196. Retrieved from http://ijello.org/Volume3/IJKLOv3p185-196Whatley367.pdf

Zhang, D., Zhou, L., Briggs, R. O., \& Nunamaker, J. F. (2006). Instructional video in e-learning: Assessing the impact of interactive video on learning effectiveness. Information \& Management, 43, 15-27. Retrieved from http://www.qou.edu/arabic/researchProgram/eLearningResearchs/instructional.pdf 


\section{Appendix}

\section{Survey Used with All Video Designs}

\begin{tabular}{|c|c|}
\hline $\begin{array}{c}\text { Please } \\
\text { place a } \checkmark \\
\text { in one of } \\
\text { these } \\
\text { columns: } \\
\text { YES or NO }\end{array}$ & Video Use Survey \\
\hline & Issue: Video Availability \\
\hline & $\begin{array}{l}\text { 1. Did the online availability of the videos lessen their use by you - either because you } \\
\text { had to view them in a campus lab, because you have a dialup internet connection that } \\
\text { makes viewing videos difficult, or for some other reason? }\end{array}$ \\
\hline & 2. Would having the videos on a CD cause you to use them more? \\
\hline & Issue: Frequency of Video Use \\
\hline & 3. Did you use the videos to review the syllabus? \\
\hline & $\begin{array}{l}\text { 4. Did you use the videos to review the characteristics of or learn how to use the grade } \\
\text { book? }\end{array}$ \\
\hline & 5. Did you use the videos, at least several times, as the textbook chapters were covered? \\
\hline & Issue: General Nature of Video Use with Chapter Coverage \\
\hline & $\begin{array}{l}\text { 6. When using the videos, did you view a chapter video BEFORE the lecture on a chap- } \\
\text { ter? }\end{array}$ \\
\hline & $\begin{array}{l}\text { 7. When using the videos, did you view a chapter video AFTER the lecture on a chap- } \\
\text { ter? }\end{array}$ \\
\hline & 8. When using the videos, did you use them simply to see what was there? \\
\hline & 9. When using the videos, did you use them before looking at the textbook chapter? \\
\hline & 10. When using the videos, did you use them to help do the homework? \\
\hline & $\begin{array}{l}\text { 11. When using the videos, did you use them to help prepare for homework/lecture ex- } \\
\text { ams? }\end{array}$ \\
\hline & 12. When using the videos, did you use them to help prepare for midterm exams? \\
\hline & Issue: Specific Nature of Help from Videos \\
\hline & 13. Did the videos help you determine what was important to know from the textbook? \\
\hline & 14. Did the videos help understand the lecture presentation of concepts and problems? \\
\hline & 15. Did the videos help understand how to do the homework problems? \\
\hline & 16. Did the videos help prepare for the homework/lecture exams? \\
\hline & 17. Did the videos help prepare for the midterm exams? \\
\hline & 18. Did the videos provide any tutoring help for you? \\
\hline
\end{tabular}




\begin{tabular}{|l|l|l|}
\hline & \begin{tabular}{l} 
Issue: Video Importance To Your Grade (what you think will happen by course-end) \\
\hline
\end{tabular} & \begin{tabular}{l} 
19. Without the videos, I may not have passed this class. \\
\hline
\end{tabular} \\
\hline & 21. The videos made it easier to earn the grade I received. \\
\hline
\end{tabular}

\section{Biography}

H. David Brecht is an Emeritus Professor of Accounting as of June 2012. This study was undertaken while a Professor of Accounting at California State University, Sacramento. His principal areas of interest have varied over the years - from managerial accounting with emphases on behavioral/organizational dynamics and computer information systems, to auditing, accounting information systems, and currently pedagogy using information technology in teaching financial accounting. He has published in academic and professional journals in all of these areas. 